\title{
We should not let families stop organ donation from their dead relatives
}

The author's position and address were out of date in this Personal View (BMJ 2012;345:e5275, doi:10.1136/bmj.e5275). David Shaw is now honorary lecturer, Division of Applied

Health Sciences, University of Aberdeen, Aberdeen AB25 2ZD. 